Editor's Note: These short reviews of recent JNeurosci articles, written exclusively by students or postdoctoral fellows, summarize the important findings of the paper and provide additional insight and commentary. If the authors of the highlighted article have written a response to the Journal Club, the response can be found by viewing the Journal Club at www.jneurosci.org. For more information on the format, review process, and purpose of Journal Club articles, please see http://jneurosci.org/content/ preparing-manuscript\#journalclub.

\title{
Can Magnetic Resonance Imaging Reveal the Neural Signatures of Dietary Self-Control?
}

\author{
- Cassandra J. Lowe $\mathrm{e}^{1,2}$ and $\oplus^{-A m y}$ C. Reichelt ${ }^{1,3}$ \\ ${ }^{1}$ BrainsCAN, Western Interdisciplinary Research Building, ${ }^{2}$ Brain and Mind Institute, Department of Psychology, and ${ }^{3}$ Robarts Research Institute, \\ University of Western Ontario, London, Ontario N6A 5B7, Canada \\ Review of Schmidt et al.
}

The modern "obesogenic" environment is characterized by an abundance of readily available hyperpalatable, energy-dense foods. These foods are highly valued and extremely rewarding: exposure to these foods and associated cues activates a diverse brain network underlying reward processing and valuation (Stice and Yokum, 2016). Such reward-related cortical and subcortical responsivity is thought to override homeostatic processes, evoking overconsumption in the absence of hunger. This is of concern because excessive consumption of obesogenic foods rather than healthier alternatives is a primary factor underlying the current obesity epidemic (Crino et al., 2015).

How then do individuals maintain a healthy diet in the modern food-rich environment? Healthy dietary habits involve the consistent selection of less appealing, but more nutritious, foods over more tempting ones. Individuals vary substantially in their ability to exercise such dietary regulation, and this variability is thought to be associated with differences

Received Aug. 1, 2018; revised Nov. 15, 2018; accepted Nov. 19, 2018.

C.J.L. and A.C.R. are the recipients of BrainsCAN Postdoctoral Fellowships at The University of Western Ontario, funded by the Canada First Research Excellence Fund.

The authors declare no competing financial interests.

Correspondence should be addressed to Amy C. Reichelt at areiche4@uwo.ca.

https://doi.org/10.1523/JNEUROSCl.1972-18.2018

Copyright $\odot 2019$ the authors $\quad 0270-6474 / 19 / 390581-03 \$ 15.00 / 0$ in the structural and functional integrity of the prefrontal cortex (PFC). That is, maintaining healthy dietary habits may be particularly dependent on the ability to inhibit visceral and autonomic responses (e.g., food cravings) to appetitive caloriedense foods, which in turn depends on cognitive control mechanisms mediated by the PFC (Vainik et al., 2013).

Within the PFC, the dorsolateral PFC (dlPFC) is thought to a play a critical role in the "top-down" control over actions (MacDonald et al., 2000). Specifically, the cognitive control mechanisms implemented by the dlPFC are proposed to work in tandem with the striatum and ventromedial PFC (vmPFC) to regulate the valuation of appetitive rewards, allowing the selection of foods on the basis of health rather than taste (Hare et al., 2009). Decreased regulatory control from the dlPFC in conjunction with stronger reward valuation inputs from the vmPFC may override health goals, increasing the likelihood that individuals will select food items on the basis of taste rather than healthiness (Hare et al., 2009). Repetitive transcranial magnetic stimulation (rTMS) has been used to decrease cortical activity in the left dlPFC, allowing examination of the relationship between dIPFC activity and the regulation of eating behavior. Following active rTMS, participants reported stronger cravings for high-calorie food items, consumed significantly more palat- able calorie-dense foods in a taste test, and showed significant reductions in task performance on standardized measures of inhibitory control (i.e., Stroop and Flanker tasks; Lowe et al., 2014, 2018). A mediation analysis revealed that the increased palatable food consumption following left dlPFC rTMS was due to reduced inhibitory control, leading to the conclusion that dlPFC activity has a key function in regulating palatable food consumption (Lowe et al., 2018).

In a recent study, Schmidt et al. (2018) sought to expand on these findings by examining whether individual differences in dietary self-regulation were also associated with neuroanatomical differences within dlPFC and vmPFC, measured by magnetic resonance imaging (MRI). Specifically, the authors integrated voxelbased morphometry and structural data from three studies examining individuals' subjective appraisals of the relative "healthiness" of food images. These results were generalized to a fourth dataset that examined dietary self-control through a task interrogating how much money participants would be willing to pay for certain foods either with the instruction to mentally "distance themselves" from urges to consume desirable foods or without any cognitive regulation. Results indicated that the combined volume of the dIPFC and vmPFC predicted dietary self-regulatory success (i.e., how much participants re- 
ported that they would like to eat a food item based on health or taste ratings). It was therefore posited that the increased gray matter volumes of the vmPFC and dlPFC were neural substrates of regulatory success when focusing on the healthiness of food. This complements previous work that found obesity to be associated with reduced gray matter volumes in the anterior cingulate, vmPFC, orbitofrontal cortex (OFC), and inferior parietal and temporal cortices - other key regions associated with dietary self-regulation and cognitive control (García-García et al., 2018)_suggesting that lower gray matter volume might impair dietary selfregulation, leading to obesity.

What explains the link between PFC volume and dietary control? The critical role of the PFC in regulating striatal reward signals to override the temptation to consume highly palatable, but unhealthy foods has been functionally demonstrated by optogenetic elevation of PFC activity, which evoked the suppression of striatal reward-related neural signals (Ferenczi et al., 2016). A more active PFC would be more effective at suppressing food rewards in the striatum and vmPFC. Therefore, Schimdt et al. (2018) observation of increased gray matter volume may reflect increased dendritic length, complexity, and spine density in the dlPFC and vmPFC stemming from neuroplasticity related to increased activity (Markham and Greenough, 2004; Kasai et al., 2010). However, gray matter volumes may not be the most accurate reflection of cortical structure and function. For instance, a recent MRI study demonstrated that the density, rather than the volume, of PFC gray matter is critical to the optimization of cognitive control (Gennatas et al., 2017). Another study (Breukelaar et al., 2017) found that decreased gray matter volume within regions of the cognitive control network (dlPFC, vmPFC, anterior cingulate, and parietal cortex) was correlated with improved performance on executive function tasks. Likewise, Takeuchi et al. (2017) demonstrated that wholebrain gray matter volume was associated with improved cognitive performance in Stroop interference and working memory tasks, but there was no significant association between task performance and gray matter volume in predefined cortical areas, including the dlPFC. Therefore, how gray matter volume in the dlPFC and vmPFC is related to enhanced dietary regulation abilities is still to be determined. Future studies should examine whether regional changes in gray matter volume and altered functionality across cortical regions are associated with diet success.

It is also possible that white matter tract integrity and connectivity between regions are better predictors of cognitive control and obesity than gray matter volumes. The integrity of the white matter tracts connecting the vmPFC and ventrolateral PFC with posterior cortices are associated with executive function task performance (Smolker et al., 2015). Moreover, decreased integrity of white matter tracts between the inferior frontal gyrus (IFG) and OFC was negatively associated with body fat percentages in chronic dieters (Chen et al., 2017). Therefore, reductions in white matter integrity along this tract may predispose individuals to overconsume appetitive high-calorie foods by limiting the ability of the IFG, a region associated with executive control, to override reward signals within the OFC. Given that the ability of the dlPFC to exert control over value signals in the vmPFC is associated with individual differences in dietary self-regulation (Hare et al., 2009), future research should investigate whether this association is related to the integrity of white matter tracts connecting these two areas.

Another important question is whether developmental factors underlie differences in dlPFC and vmPFC structural integrity. The developing brain is highly susceptible to environmental insults, including nutrition, which can derail the natural course of brain maturation. The PFC is one of the last brain regions to mature; thus, synaptic pruning and refinement of white matter tracts across adolescence leads to enduring changes in connectivity between reward signaling and cognitive control areas (Giedd et al., 1999). Rodent studies have demonstrated that excessive consumption of obesogenic foods during adolescence negatively impacts function in medial PFC (a region homologous to the human dlPFC), resulting in impaired behavioral flexibility (Labouesse et al., 2017) and decision-making (Reichelt et al., 2015). Correspondingly, in humans, a history of excessive obesogenic food consumption is associated with reduced sensitivity to value changes of food rewards, which can lead to habitual or compulsive overeating - hallmarks of behavioral dysregulation and loss of control (Horstmann et al., 2015). Considering the importance of self-regulation in dietary success, diet-evoked variability in the functional calibration of the PFC may be a critical mechanism underpinning maladaptive eating behaviors. Since regional activity, like connectivity, can change over time, the dlPFC and vmPFC may be targets for interventions promoting healthy food choices.

Although the findings by Schmidt et al. (2018) highlighted the role that structural differences play in dietary self-regulation, more work is necessary to elucidate how these structural differences translate into functional differences in cortical responsivity during food choices. Comparing resting-state and task-dependent activity levels in the vmPFC and dlPFC between groups of individuals who are successful at making healthy food choices and those who are not could provide a starting point for cognitive training interventions to optimize plasticity. Following dietary regulation training, volumetric changes to the vmPFC and dlPFC combined with structural and functional connectivity may provide a measure of activity-driven neuroplasticity processes in neural networks essential for self-control. Thus, the neurobiological insight provided by functional and structural imaging could identify ways to break habitual eating behaviors and facilitate dietary decision-making to support dietary modification.

\section{References}

Breukelaar IA, Antees C, Grieve SM, Foster SL, Gomes L, Williams LM, Korgaonkar MS (2017) Cognitive control network anatomy correlates with neurocognitive behavior: a longitudinal study. Hum Brain Mapp 38:631643. CrossRef Medline

Chen PA, Chavez RS, Heatherton TF (2017) Structural integrity between executive control and reward regions of the brain predicts body fat percentage in chronic dieters. Cogn Neurosci 8:162-166. CrossRef Medline

Crino M, Sacks G, Vandevijvere S, Swinburn B, Neal B (2015) The influence on population weight gain and obesity of the macronutrient composition and energy density of the food supply. Curr Obes Rep 4:1-10. CrossRef Medline

Ferenczi EA, Zalocusky KA, Liston C, Grosenick L, Warden MR, Amatya D, Katovich K, Mehta H, Patenaude B, Ramakrishnan C, Kalanithi P, Etkin A, Knutson B, Glover GH, Deisseroth K (2016) Prefrontal cortical regulation of brainwide circuit dynamics and reward-related behavior. Science 351: aac9698. CrossRef Medline

García-García I, Michaud A, Dadar M, Zeighami Y, Neseliler S, Collins DL, Dagher A (2018) Neuroanatomical differences in obesity: meta-analytic findings and their validation in an independent dataset. Int J Obes (Lond). Advance online publication. Retrieved November 25, 2018. doi:10.1038/s41366-0180164-4.

Gennatas ED, Avants BB, Wolf DH, Satterthwaite TD, Ruparel K, Ciric R, Hakonarson H, Gur RE, Gur RC (2017) Age-related effects and sex differences in gray matter density, volume, 
mass, and cortical thickness from childhood to young adulthood. J Neurosci 37:50655073. CrossRef Medline

Giedd JN, Blumenthal J, Jeffries NO, Castellanos FX, Liu H, Zijdenbos A, Paus T, Evans AC, Rapoport JL (1999) Brain development during childhood and adolescence: a longitudinal MRI study. Nat Neurosci 2:861863. CrossRef Medline

Hare TA, Camerer CF, Rangel A (2009) Selfcontrol in decision-making involves modulation of the vmPFC valuation system. Science 324:646-648. CrossRef Medline

Horstmann A, Dietrich A, Mathar D, Pössel M, Villringer A, Neumann J (2015) Slave to habit? obesity is associated with decreased behavioural sensitivity to reward devaluation. Appetite 87:175-183. CrossRef Medline

Kasai H, Fukuda M, Watanabe S, Hayashi-Takagi A, Noguchi J (2010) Structural dynamics of dendritic spines in memory and cognition. Trends Neurosci 33:121-129. CrossRef Medline

Labouesse MA, Lassalle O, Richetto J, Iafrati J, Weber-Stadlbauer U, Notter T, Gschwind T, Pujadas L, Soriano E, Reichelt AC, Labouesse C, Langhans W, Chavis P, Meyer U (2017) Hypervulnerability of the adolescent prefrontal cortex to nutritional stress via reelin defi- ciency. Mol Psychiatry 22:961-971. CrossRef Medline

Lowe CJ, Hall PA, Staines WR (2014) The effects of continuous theta burst stimulation to the left dorsolateral prefrontal cortex on executive function, food cravings, and snack food consumption. Psychosom Med 76:503-511. CrossRef Medline

Lowe CJ, Staines WR, Manocchio F, Hall PA (2018) The neurocognitive mechanisms underlying food cravings and snack food consumption. A combined continuous theta burst stimulation (cTBS) and EEG study. Neuroimage 177:45-58. CrossRef Medline

MacDonald AW, Cohen JD, Stenger VA, Carter CS (2000) Dissociating the role of the dorsolateral prefrontal and anterior cingulate cortex in cognitive control. Science 288:18351838. CrossRef Medline

Markham JA, Greenough WT (2004) Experiencedriven brain plasticity: beyond the synapse. Neuron Glia Biol 1:351-363. CrossRef Medline

Reichelt AC, Killcross S, Hambly LD, Morris MJ, Westbrook RF (2015) Impact of adolescent sucrose access on cognitive control, recognition memory, and parvalbumin immunoreactivity. Learn Mem 22:215-224. CrossRef Medline

Schmidt L, Tusche A, Manoharan N, Hutcherson C, Hare T, Plassmann H (2018) Neuroanat- omy of the vmPFC and dlPFC predicts individual differences in cognitive regulation during dietary self-control across regulation strategies. J Neurosci 38:5799-5806. CrossRef Medline

Smolker HR, Depue BE, Reineberg AE, Orr JM, Banich MT (2015) Individual differences in regional prefrontal gray matter morphometry and fractional anisotropy are associated with different constructs of executive function. Brain Struct Funct 220:1291-1306. CrossRef Medline

Stice E, Yokum S (2016) Neural vulnerability that increase risk for future weight gain. Psychol Bull 142:447-471. CrossRef Medline

Takeuchi H, Taki Y, Nouchi R, Yokoyama R, Kotozaki Y, Nakagawa S, Sekiguchi A, Iizuka K, Yamamoto Y, Hanawa S, Araki T, Miyauchi CM, Shinada T, Sakaki K, Sassa Y, Nozawa T, Ikeda S, Yokota S, Daniele M, Kawashima R (2017) Global associations between regional gray matter volume and diverse complex cognitive functions: evidence from a large sample study. Sci Rep 7:10014. CrossRef Medline

Vainik U, Dagher A, Dubé L, Fellows LK (2013) Neurobehavioural correlates of body mass index and eating behaviours in adults: a systematic review. Neurosci Biobehav Rev 37: 279-299. CrossRef Medline 